It was the second notable victory for the animal-rights extremists since the Cambridge decision. Work on a new animal house at the University of Oxford has been stalled for over a year, after threats and vandalism forced contractors to pull out. The increased support for animal research seen in the media and in public opinion polls, and highlighted in our editorial, has continued during that period. But the activists have become more focused and strategicand more successful.

Analysis of the new tactics suggests that the fight against the extremists may take longer to win than anticipated. Activists have been concentrating on a small number of secondary targets, such as financial firms that act for animal testing laboratories. Attacks to individuals' homes are common. It is impossible for the police to defend such a wide range of targets and, as a consequence, many companies have ended associations with animal researchers and breeders. And it is not just British researchers who should be concerned: similar tactics are becoming increasingly common in the United States, where the FBI is investigating more than 100 cases, many involving arson.

Yet there is plenty to suggest that the extremists' actions will only prolong their fight, not allow them to win it. New UK legislation, aimed at punishing protestors who set out to cause economic damage to companies, came into force this summer. Perhaps because of publicity surrounding the new offences, attacks on company and private property connected with animal research fell sharply even before the new powers became law.

In the longer term, police must infiltrate the activists as they would any other extremist organization. It is a welcome sign that the UK government has made animal activists a major focus for the National Extremism Tactical Co-ordination Unit, a policing body established in March 2004.

Action from the research community is the final front in the fight. Here the news is encouraging, although a great deal remains to be done. A decade ago, the Research Defence Society (now known as the RDS), which supports the medical use of animals, could call on just two researchers when asked to supply scientists for media interviews. That number now stands at 25. This is still far too few,
"More than 500 prominent scientists have put their names to adeclaration released last week that backs animal research." given that thousands of researchers in Britain use animals in their work. But it is a start. It is also good to see that more than $\mathbf{5 0 0}$ prominent scientists have put their names to an RDS statement released last week, the Declaration on Animals in Medical Research, that backs animal research.

Perhaps the only group not pulling its weight is the university sector. Some universities encourage researchers to speak out, but they are in the minority. Universities have just as a big a stake in animal research as any other science organization. This reluctance to talk to the public about their research merely plays into the hands of the extremists, who would be delighted to see scientists stay silent.

\section{Three cheers}

\section{This issue of Nature includes several reasons for editorial celebration.}

T his is, above all, the issue of the chimp. It is not just the formal publication of the genome and related analyses, which would be ample cause for celebration. By a happy coincidence, the first fossil chimp has been found. This cornucopia of new science is introduced on page 47 . Elsewhere in the issue, and in our freeaccess news service (www.nature.com/news), readers can find a range of discussions of comparative genomics, threats to chimp populations, a timeline of chimp research, and an introduction to famous chimps.

Alongside all this progress in chimp biology there are some provocative but essential questions raised about the future of conservation and of research, in Commentaries by Pascal Gagneux and colleagues (on page 27) and by John VandeBerg and Stuart Zola (on page 30).

What else to celebrate? In its role as a journal, Nature has historically focused on the formal reporting of research results and, like all journals, has ignored the process of discovery. In one small way we breached that barrier a few years ago by inviting authors to spell out their individual contributions at the end of the paper. After a slow start, more and more authors are responding to this invitation.

This week we go one step further, with the launch of our weekly
'Authors' page (page xiii). This is intended to show the joys, deadends and happenstance that lead to the 'eureka moment' of discovery. In 'Making the Paper', two authors tell how a hunt for some stone tools led them to a chimp tooth that has major implications for evolution. The 'Abstractions' column highlights individual contributions. This week, a computer programmer and database administrator recounts how she wrestled with an overabundance of chimp and human genome data and explains the difficulties in running a comparative analysis. Finally, 'Quantified' discusses some timely statistical data about Nature papers and provides some context behind the numbers.

So much for science fact. Regular readers will know that we have also been publishing a series of short science-fiction stories under the 'Futures' banner. The current series - a
"The current series of 'Futures' concentrates on developments that might occur within the next 50 years, roaming widely from the effects of climate change to how the dead might bereunited as spam filters." successor to that published at the turn of the Millennium concentrates on developments that might occur within the next 50 years, roaming widely from the effects of climate change and genetic engineering to how the dead might be reunited as spam filters. The third cheer this week is for recognition by the European Science Fiction Society, which has bestowed its award of Best Publisher to the series editor Henry Gee and to Nature. 